\title{
SIMULATION OF AERIAL SUPRESSION TASKS IN WILDFIRE EVENTS INTEGRATED WITH GISFIRE SIMULATOR
}

\author{
Jaume Figueras i Jové \\ Antoni Guasch i Petit \\ inLab FIB \\ Universitat Politècnica de Catalunya \\ Campus Nord, Edifici B5 \\ C/ Jordi Girona 1-3, Barcelona, E-08034, SPAIN
}

\author{
Josep Casanovas-García \\ Barcelona Supercomputing Center \\ Universitat Politècnica de Catalunya \\ Campus Nord, Edifici Nexus 2 \\ C/ Jordi Girona 29, Barcelona, E-08034, SPAIN
}

\begin{abstract}
Wildfire simulation tools focus on how fire spreads in the natural environment. Simulation of fire containment operations can provide managers with a tool that combine wildfire evolution with suppression operations. Combined simulation tools are useful to evaluate different strategies and tactics in firefighting wildfires. This paper presents the modelling and simulation of aerial containment operations integrated into a wildfire spread simulator. A continuous space wildfire spread simulator has been used for fire spread simulation. This simulator called GisFIRE integrates aerial operations and uses QGIS geographical information system to integrate both simulation tools with geographical information. The information system combines air facilities locations, usable bodies of water, and other relevant geo-information with the simulation procedures. Open source software is a requirement to allow integration of different software packages and usage of OGC standards to represent geographical information.
\end{abstract}

\section{INTRODUCTION}

Wildfires are a complex phenomenon that pose in risk natural environment, properties, infrastructure and human lives. A decision support system to help firefighter managers take decisions easily and evaluate the risks comparing different actuation alternatives can improve the suppression operations. During a wildfire event, firemen officers have to take many decisions regarding fire containment and suppression operations and also about the logistics involved in these operations. Problems such as the aerial fire-attack planning or engines water provisioning are problems suitable to be automated. Under this framework, the ability to combine a wildfire spread simulation with suppression activities simulation can help officers take more informed decisions and evaluate the risks comparing different actuation alternatives that can improve the suppression operations management training or decision making.

This paper focuses on the integration of aerial operations simulation into the GisFIRE simulation environment, a wildfire spread simulator built into the QGIS geographical information system. This work is an approach to simulate and evaluate aerial wildfire operations using agent based modelling. The usage of geographical information such as the airport and aerodrome information or the water bodies locations where aerial resources can refill its tanks allow the usage of real environments with the simulation.

The QGIS geographical information system can be extended with a plug-in system or with scripting system, both of them using the Python programming language, Steiniger and Hunter (2013). This programming ability allow the integration of agent based simulation libraries into the system. Also, the usage of a well-known GIS tool improves the development speed and provide an application user interface out of the box. 
The integration of an agent based modelling and simulation toolkit and with the proposed system has to fit with the programming requirements, MESA (Masad and Kazil 2015), implements an ABMS as a Python library that can communicate with QGIS environment.

The GisFIRE plug-in links the data provided by the QGIS environment and synchronize the two simulators that generate a fire perimeter evolution, Figure 1.

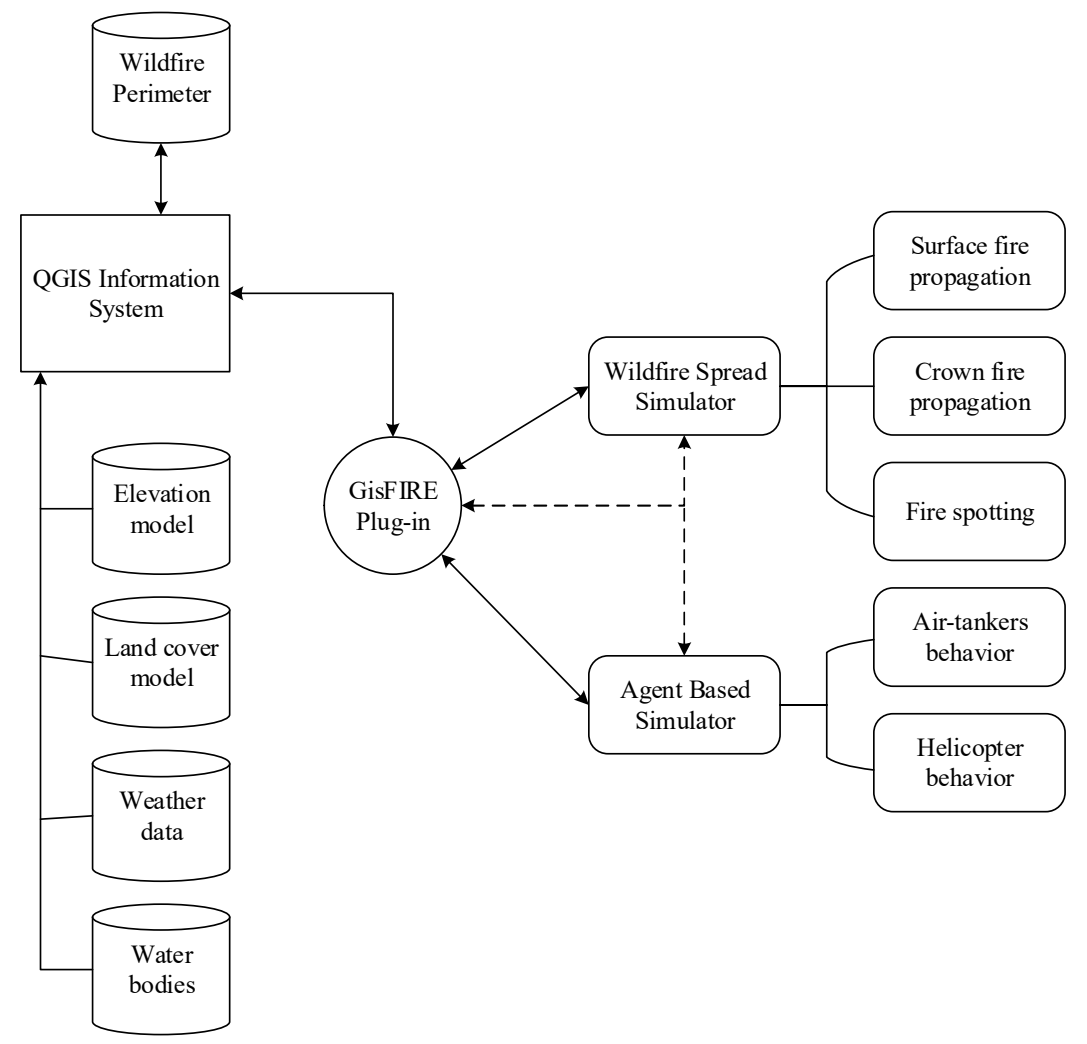

Figure 1: Component diagram of GisFIRE.

This paper is organized in as follows: Section 2 analyze the previous work in wildfire modelling and simulation and wildfire suppression simulation by ground and aerial means; Section 3 present the tactics and simulation algorithms for simulation aerial firefighting; Section 4 presents the experiments conducted and, section 5 present the conclusions and further work.

\section{RELATED WORK}

Wildfire models try to explain the complex phenomenon of how a fire propagates through the natural environment. There exist a huge set of wildfire spread simulators. Papadopoulos and Pavlidou (2011) reviewed and compared almost all of the simulation software, classifying and evaluating them. Wildfire simulators can be divided in three main categories:

- Physical or quasi-physical, Sullivan (2009a): are the models that represent physical and chemistry processes or only the physical processes but not the chemical respectively

- Empirical or quasi-empirical, Sullivan (2009b): are the models that do not represent any physical or chemical process or only a part of them respectively and rely on statistics to model the fire behavior

- Simulation and mathematical, Sullivan (2009c): are the models that use accepted mathematical functions and concepts not related with wildfire but its behavior have apparent similarities. 


\subsection{Wildfire Simulators}

Depending on the fire agency and country one or another modelling technique and simulator tool is used. The most important simulators referenced are Papadopoulos and Pavlidou (2011):

- Prometheus: (Tymstra et al. 2010) - Canada. Prometheus is a deterministic simulator that uses differential equations Richards (1995) to calculate the Rate of Spread (ROS) and the Huygens' principle Sneddon et al. (1951) of wave propagation. (The Huygens' principle applied to wildfire propagation is a simplification of the perimeter propagation using superposition of waves. The current perimeter is sampled and at each sample point a new and independent fire is propagated. Then the new expanded perimeter is calculated as the resulting perimeter of superposing all the new propagated fires in the samples.) It can be classified as quasi-physical and mathematical since it uses physical properties of combustion to calculate the ROS and the optical wave propagation to compute the fire perimeter.

- Phoenix: (Tolhurst et al. 2008; Spark Miller et al. 2015) - Australia. First, the Phoenix system uses the CSIRO behavior model developed by Cheney et al. (1998) for grassland and the work started by McArthur (1962) and beyond for forests. The spread model is also based on the Huygens' principle but modified to work with a terrain cell division. Second, the Spark system has been built to provide user-defined models and a study workflow Phoenix is no longer maintained and Spark is the substitution tool. The models that are used to determine the Rate of Spread of the wildfire are quasi-physical but with modifications as explained in Tolhurst et al. (2008) that introduce changes to inputs depending on solar radiation, spot firing, etc. that introduce empirical models.

- FARSITE: (Finney 2004) - USA. FARSITE is now integrated inside FlamMap (Finney 2006) and defined by Papadopoulos and Pavlidou (2011) as the best reviewed wildfire spread simulator. FARSITE uses the Rothermell (1972) equations to calculate the spread Rate (ROS) and the Huygens' principle as it does Prometheus using Richards (1990) differential equations. Rothermell equations present both quasi-empirical behavior since they model the fire chemistry and behavior from empirical experimentation in wind tunnels.

\subsection{Simulation of Suppression Operations}

The first efforts to simulate air-tanker suppression in wildfires were conducted by Simard (1979) that implemented the AIRPRO simulation models that also selected tactics to firefight. Duff and Tolhurst (2015) review the wildfire suppression modelling. There are many tools that model wildfire suppression but just three simulators integrate the dynamics of fire behavior with the dynamics of realistic suppression:

- DEVS-FIRE: (Hu et al. 2012; Hu and Ntaimo 2009; Hu and Sun 2007) Hybrid simulation models with cellular automata to simulate wildfire spread and agent based simulation for the suppression tasks. Suppressions tactics are: perimeter tracking at the rear and perimeter tracking at the flanks. Both can be direct and indirect attacks and does not connect to any dispatcher.

- Phoenix: (Tolhurst et al. 2008) Huygens' principle for wildfire spread simulation and fixed tactic: perimeter tracking at the rear with direct attack. Does not connect to any dispatcher.

- FARSITE: (Finney 2004) Hybrid simulation models combining quasi-empirical and mathematical approaches for spread simulation and agent based simulation for suppression tasks. Suppression tactics are: direct attack, parallel attack and aerial attack (implemented as temporal fire- 
impermeable barriers) Modelers decide the location of the suppression resources manually. Does not connect to any dispatcher.

Different tactics and strategy for fire suppression such as direct, indirect or parallel attack can be found in NFIC (1996).

In all the suppression operation described above the systems do not connect to any dispatcher or decision support system, so the modeler has to deal with the location of the suppression teams or the airtanker drop locations. Section 3.2 will present an algorithm to determine the air-tanker drop points. The modeler will have to decide how many tankers and the type of tankers it will dispatch, but the simulator will determine the drop locations.

\subsection{Air Operations Simulation}

Simulation of aerial operations in wildfire events are poorly modelled or not taken into account. As explained in section 2.2 only FARSITE has implemented the simulation of aerial attack operations. Finney et al. (1997) simulate the aerial drops by using the relationships between the type of aircraft and coverage level of the drop that specify a particular production length of retardant on the ground. The coverage level is the quantity of water or retardant dropped per area unit. The coverage level has to be communicated to the pilots and they will operate the tank doors accordingly. A low coverage level produce longer production lines because the aircraft doors are slightly open. A high coverage level produce shorter production lines because the air-tanker doors are fully open. The production length is the length or fire that has been suppressed. Ground crews use the production rate as length of fire suppressed per time unit while air crews use just the production length per drop.

The relationships between the type of aircraft and coverage level have been studied by George (1981, 1992) that elaborated complex charts to determine the production length by aircraft model and coverage level. In further studies, Fried and Fried (1996) simplified the previous work and determined only two types of drops in aerial operations: Air tanker drops with a production length of 161 meters (8 chains) and helicopter drops with a production length of 60 meters (3 chains). Finally NFIC (1996) explain the air operations in the USA by recommending the use of retardant and typifying a coverage level depending on the type of fuel. The study provides a table with the production length of retardant drops depending on the air tanker capacity and coverage level.

The pattern of the drop has also been modelled, Suter (2000) discussed the statistical matters and experiment design to characterize air-tanker drops. Legendre et al. (2014) and Martínez Oller (2015) conducted a series of experiments with air-tankers and helicopters. These studies conclude that the water drops are stadium shaped, which length is controlled by the coverage level and speed and a standard width of 30 meters for air-tankers and 5 meters for helicopters (both ventral tank or bambi bucket).

There is a huge difference in the type of resources used in aerial operations between USA and other countries. The USDA (2019) standards for air-tanker operations take into account air-tankers with capacity of more than 36,000 liters. In Europe, Pierard and Jarvis (2010) report of different countries state that airtankers capacity are up to 5,500 liters, most of them are helicopters with capacities up to 1,200 liters.

Different countries also have different aerial regulations, in the USA, NFIC (1996) the only limitation in aerial operations planning are the refueling of the aircraft and the pilot duty hours, but other countries can be more restrictive. Spain has one of the most restrictive regulations described in General Directorate of Civil Aviation (1995) where pilots have a complex pattern of rests each three flying hours, but also with a daily, weekly and monthly cumulative patterns. For the simulation process, the different regulations are not taken into account, because the aircraft and pilot considerations can be calculated by an optimization process to fit the simulation requirements. 


\section{WILDFIRE AERIAL OPERATIONS}

Different regulations and procedures that are applied in different countries. To model aerial suppression activities, the methodology that is applied in Spain by the Catalan Firefighting Agency is used Borderas Ruiz et al. (2014). The aerial operations are dispatched depending on the size of the fire. Figure 2a shows that for small fires there is only one attack area. Also the aerial areas for safe operation are shown. Figure $2 \mathrm{~b}$ shows the four attack areas that are considered in medium fires. Finally Figure $2 \mathrm{c}$ shows the six attack areas division for large fires. There is no literature for aerial attack in megafires that are beginning to appear in this last decade. All of them use the head of the fire (the zone where the fire grows faster, usually aligned with the dominant wind) as the main reference. The attack area divisions determine the aerial space usage and the attack area inside the division. Depending on the tactics applied aerial operations can perform different attack types Caamaño Azcárate (2008): Direct attack to the fire front (head, flank or tail attack) or indirect attack to support ground operations, normally widening burning to protect sensible areas or to create a firewall. For this simulation only direct attack is considered, leaving the integration of ground and aerial tactics to a future work.

\subsection{GisFIRE propagation model}

GisFIRE uses a combination of propagation models. It uses the Rothermell (1972) equations to calculate the spread Rate (ROS) and the Huygens' principle using Richards (1990) differential equations. To overcome the loop problems described in Richards (1990) it uses the procedures described in Barber (2009) and Bose et al. (2020) to untangle topological loops and crossings

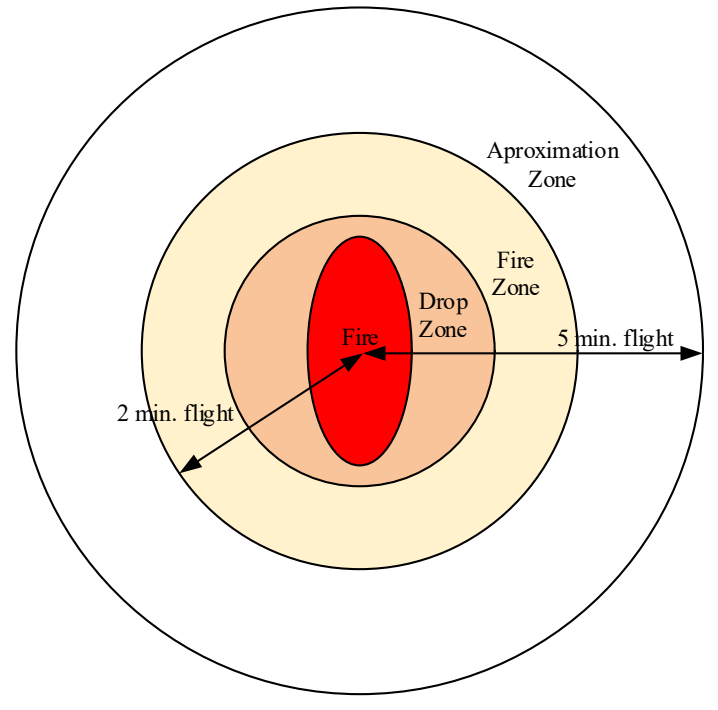

Figure 2a: Small fire with aerial divisions.

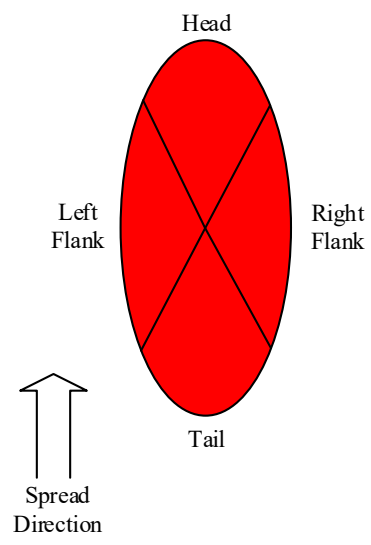

Figure 2b: Medium fire divisions.

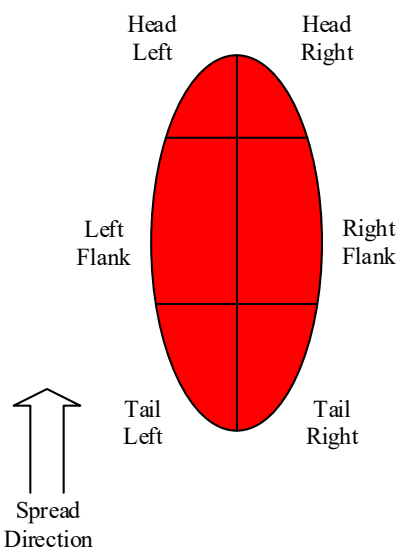

Figure 2c: Large fire divisions.

\subsection{Aerial Suppression Modelling}

The aerial direct attack modelled follow the "thirds" rule, where on third of the drop remain out of the fire front while the other two thirds try to fit on the fire front. The selection of the drop point depend on the evolution of the fire perimeter and the geometry of the drop, that depends on several factors described in section 2.3. The objective of the selection point is to minimize the burned area, and to reach this objective 
the main action that can be taken in direct attack is to block the propagation of the fire front. Independently of the divisions in the attack regions, the same objective is applied.

Based on this idea a selection algorithm has been designed, as the decision of the drop point is taken when the aerial mean enters to the fire zone assigned, that is 2 minutes flight time to the fire front, there is no need to apply any prediction of the evolution of fire neither based on wind changes or land surface properties changes. The algorithm finds the most escaped area of the perimeter that has not been attacked, apply the thirds rule and calculate the location and direction of the drop with a two-minute delay. To simplify the calculations a rectangular drop area will be used.

1. Select a perimeter area depending on the mean assigned

a. If fire is categorized as small: only one area

b. If fire is categorized as medium: head, right, left or tail

c. If fire is categorized as large: head left or right, flank left or right or tail left or right

2. Calculate a fire perimeter with no suppressed points

3. Rotate the fire perimeter to align head to north to determine the maximum propagation

4. Find all peaks of the perimeter rotated as they are the points of maximum propagation

5. Calculate the Rate of Spread and Spread Direction for all peaks

6. Calculate the peaks new positions based on the rate and spread direction

7. Select the north-most peak as the drop point

8. Calculate the surface covered by the drop depending on the aerial mean type

9. Rotate the surface to find the maximum perimeter covered

a. Sample a set of rotations with a $10^{\circ}$ step

b. Calculate the intersection of the drop with the perimeter

c. find the maximum perimeter length overlapping the different samples

The area of the fire that will be under study is the area assigned to the air -tanker or helicopter for which the drop point is calculated. First, all points of the involved perimeter that have been suppressed have to be removed from the calculation (this is a drawback of perimeter representation, this step is not necessary when working with cellular automata). A rotation (centered in the perimeter centroid) of the perimeter is applied to align the fire perimeter to the north axis. Then a peak finder algorithm is applied to find all points that are candidates of being the north-most point of the perimeter. The north-most point is selected depending on the growth rate of the fire at that point with the current wind. Finally, the drop surface is computed depending on the aerial mean type and it is rotated depending on the area selected to fins the direction in which the most length of the fire perimeter is burned by the drop (this is calculated by the intersection of the two geometries).

\subsection{Drop Points Integration with Wildfire Spread Simulation}

As shown in the introduction several layers of information are needed to simulate the spread of a wildfire. To represent the air drops, a new layer of geographical information has to be introduced to alter the propagation in the fire in the drop areas. In the calculation of the land surface properties, a new step has been added to zero the rate of spread in the fire front when a perimeter point lays on a drop area. The drop layer act as a no fuel area but it marks the perimeter points as suppressed, so they can't be burned again making an area-vanishing-time not necessary because surrounding area will be burnable as can be seen in the last step of Figure 3 where the first and second drop are surrounded again by fire. 


\section{RESULTS}

Different experiments have been conducted to test helicopter and plane capacity and with different drop frequencies. The drop distance and with values calculated by Fried and Fried (1996) are used in these experiments.

First an ignition point has been located in a homogeneous flat surface with constant wind in order to minimize the perimeter noise and make the different experiments easily comparable. Then it has been ignited and let grow free during 20 minutes, as the surface is homogeneous, flat and with constant wind, the perimeter shape propagates as a perfect ellipse. After 20 minutes helicopter water drops are simulated with a 5 minute drop frequency as shown in Figure 3. With this low frequency the fire can surround the water drop and continue its propagation. The algorithm tries to stop the escaped fire head front, but as it focuses only on the head both flanks create new escaped heads. With just one helicopter with a 5 minute frequency this fire can't be contained.

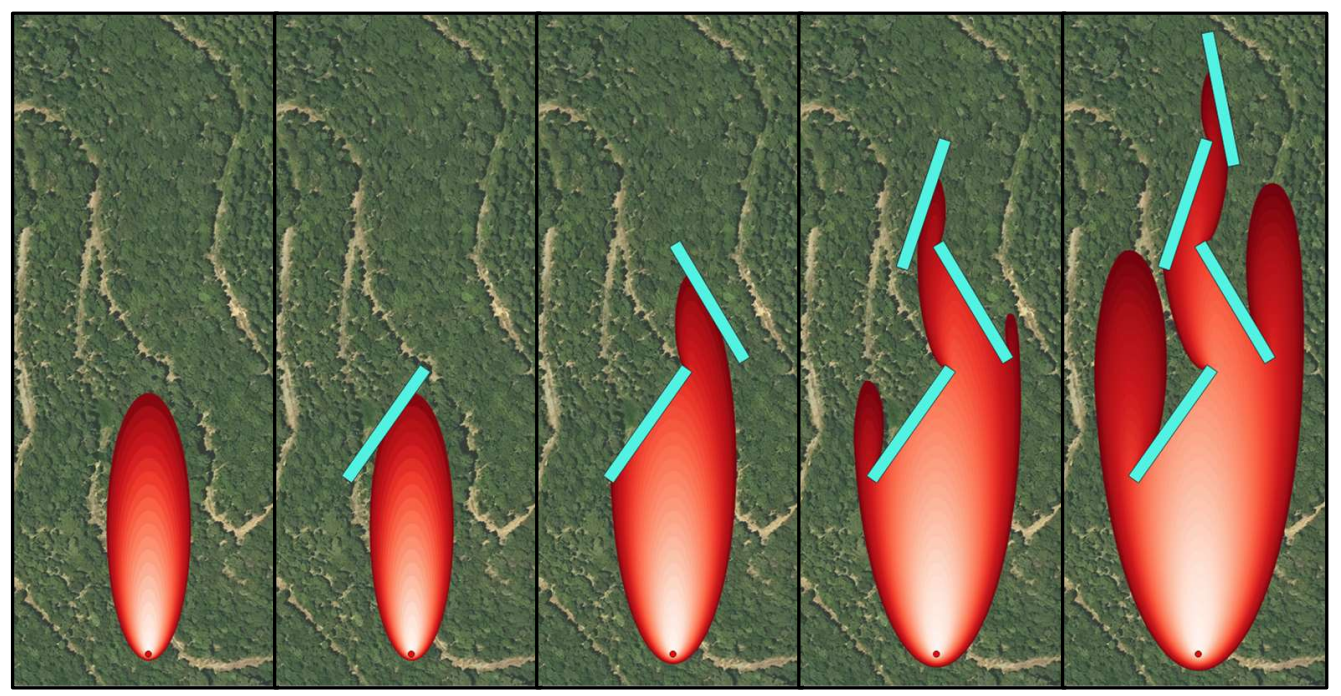

Figure 3: Helicopter drops every 5 minutes after a 20 minute wildfire ignition.

The experiment shown in Figure 4 simulate two helicopters firefighting the same scenario presented before. The resulting drop frequency is now 2.5 minutes, and although the resulting new heads from the flanks can be contained after the main head of the fire is contained. In the previous experiment described the containment did not succeeded.

Finally, a last experiment has been tested with one plane and a 5 minute frequency in the water drops. As the plane drops are longer and wider the fire perimeter can be fully contained with just four water drops. Figure 5 shows that the fire head is fully suppressed and although the spread takes into account the backfire it is not strong enough to surround the drop and create a new head from the flanks.

\section{CONCLUSIONS}

A procedure to simulate air-tanker water drops in a wildfire has been presented. At present the authors did not find a wildfire simulators with the ability to plan aerial suppression operations, so this paper focus in a first approach to simulate aerial water drops. Integration of a simulator with a geographical information system is also a new step to bring together simulation with forestry engineering. 


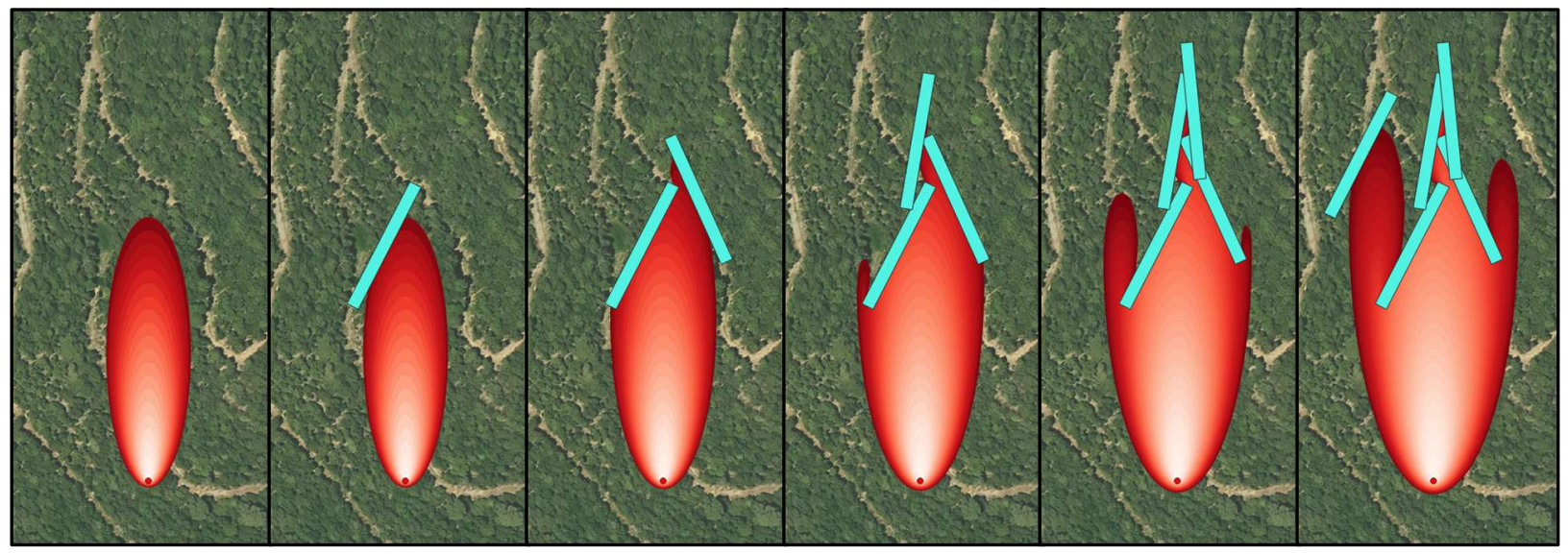

Figure 4: Helicopter drops every 2.5 minutes after a 20 minute wildfire ignition.

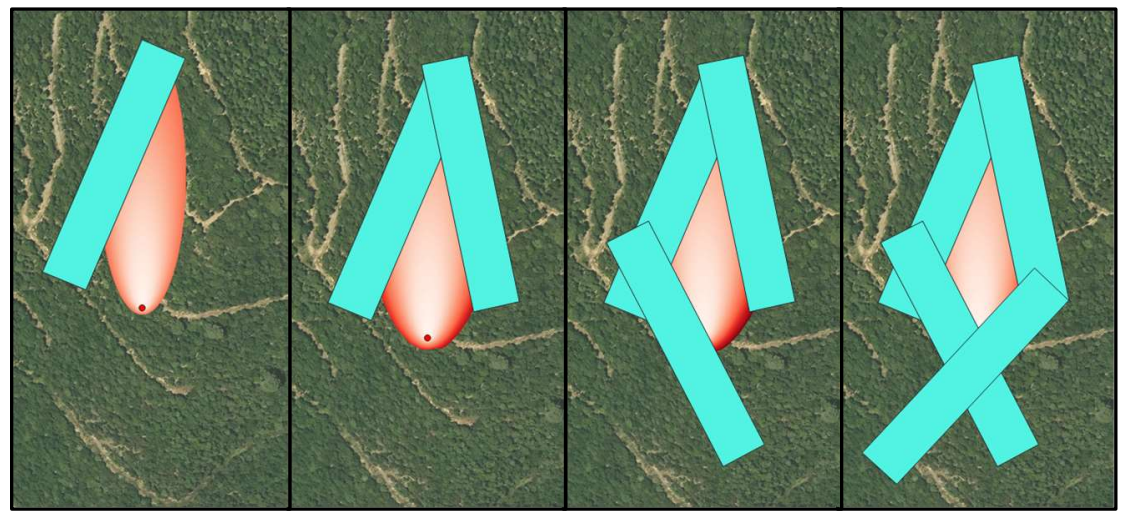

Figure 5: Plane drops every 5 minutes after a 20 minute wildfire ignition.

\section{FURTHER WORK}

Lack of validation is the weaker aspect of this study. Gu et al. (2008) propose the usage of FARSITE as a validation tool since is the most used wildfire simulator. Kelso et al. (2015) use historical data and Australis simulator to compare different simulators performances. They found inaccuracies due to bad data, bad collected data and in extreme fires. Comparing with historical data and also with FARSITE will be the most reliable way of validating. Catalan Fire Agency collects plane and helicopters traces from many years, but drop points are only collected from 2016, so a few validation experiments can be conducted.

The current simulation, create water drops in a rectangular shape. Adapting this shape to the real shape of the perimeter as pilots try to do will increase the accuracy of the drops. Information about the dynamics of the plane and helicopter are needed in order to avoid adapting to impossible shapes.

Finally, computing the real trajectory paths of the aerial means from the airport bases to the fire and selecting the most suitable water bodies to refill the tanks and bambi buckets will provide a realistic information to aerial managers in order to plan the number of aerial units needed to contain a wildfire.

\section{REFERENCES}

Barber, J. 2009. "Burning Issues with PROMETHEUS, the Canada's Wildfire Growth Simulator". Canadian Applied Math 
Quarterly 16(4):337-378

Borderas Ruiz, F., B. Aguado, J. J. Enriquez Pérez, R. Quílez Moraga, and J. J. Espadas Gutierrez. 2014. Operaciones Aéreas en Incendios Forestales Taradell: Pau Costa Foundation.

Bose, C., R. Bryce, and G. Dueck. 2009. "Untangling the Prometheus Nightmare". In 18th World IMACS Congress and MODSIM 2009 - International Congress on Modelling and Simulation: Interfacing Modelling and Simulation with Mathematical and Computational Sciences, July $13^{\text {th }}-17^{\text {th }}$, Cairns, Australia, 1-7.

Caamaño Azcárate, J. 2008. Manual de Operaciones y Coordinación de Medios Aéreos en Incendios Forestales. https://www.scribd.com/doc/57852994/Manual-de-Operaciones-y-Coordinacion-de-Medios-Aereos-en-Incendios-Forestales accessed $19^{\text {th }}$ August 2020.

Cheney, N., J. Gould, and W. Catchpole. 1998. "Prediction of Fire Spread in Grasslands". International Journal of Wildland Fire $8(1): 1-13$.

Duff, T. J., and K. G. Tolhurst. 2015. "Operational Wildfire Suppression Modelling: A Review Evaluating Development, State of the Art and Future Directions". International Journal of Wildland Fire 24(6):735-748.

Finney, M. A. 2004. "FARSITE: Fire Area Simulator - Model Development and Evaluation". USDA Forest Service - Research Papers RMRS, RMRS-RP-4, 1-36.

Finney, M. A. 2006. "An Overview of FlamMap Fire Modeling Capabilities". In Fuels Management-How to Measure Success: Conference Proceedings, edited by P. L. Andrews and B. W. Butler. 213-220. US Department of Agriculture, Forest Service, Rocky Mountain Research Station, Fort Collins, Colorado.

Finney, M., D. Sapsis, and B. Bahro. 1997. "Use of FARSITE for Simulating Fire Suppression and Analyzing Fuel Treatment Economics". In Symposium on Fire in California Ecosystems: Integrating Ecology, Prevention, and Management, November $17^{\text {th }}-20^{\text {th }}$, San Diego, California, 121-136.

Fried, J. S., and B. D. Fried. 1996. "Simulating Wildfire Containment with Realistic Tactics". Forest Science 42(3):267-281.

General Directorate of Civil Aviation 1995. "Circular Operational 16-B: On Flight Time Limitations, Maximums of Activity Air and Minimum Rest Periods for Crews". http:/www.aecaweb.com/informes/documentos/INFORMES_Y_ESTUDIOS/ anexo1aco16b.pdf accessed $19^{\text {th }}$ August 2020.

George, C. W. 1981. "Determining Airtanker Delivery Performance Using a Simpie Slide Chart-Retardant Coverage Computer". Vol. 400. US Department of Agriculture, Forest Service, Intermountain Research Station, Ogden, Utah.

George, C. W. 1992. "Improving the Performance of Fire Retardant Delivery Systems on Fixed-wing Aircraft". Vol. 400. US Department of Agriculture, Forest Service, Intermountain Research Station, Ogden, Utah.

Gu, F., X. Hu, and L. Ntaimo. 2008. "Towards Validation of DEVS-FIRE Wildfire Simulation Model". In Proceedings of the 2008 Spring Simulation Multiconference, April $14^{\text {th }}-17^{\text {th }}$, Ottawa, Canada, 355-361.

$\mathrm{Hu}$, X., and Y. Sun. 2007. "Agent-based Modeling and Simulation of Wildland Fire Suppression". In Proceedings of the 2007 Winter Simulation Conference, edited by S. G. Henderson, B. Biller, M.-H. Hsieh, J. Shortle, J. D. Tew, and R. R. Barton, 1275-1283. Piscataway, New Jersey: Institute of Electrical and Electronics Engineers, Inc.

Hu, X., and L. Ntaimo. 2009. "Integrated Simulation and Optimization for Wildfire Containment". ACM Transactions on Modeling and Computer Simulation 19(4):1-29.

$\mathrm{Hu}$, X., Y. Sun, and L. Ntaimo. 2012. "DEVS-FIRE: Design and Application of Formal Discrete Event Wildfire Spread and Suppression Models". Simulation 88(3):259-279.

Kelso, J. K., D. Mellor, M. E. Murphy, and G. J. Milne. 2015. "Techniques for Evaluating Wildfire Simulators Via the Simulation of Historical Fires Using the Australis Simulator". International Journal of Wildland Fire 24(6):784-797.

Legendre, D., R. Becker, E. Alméras, and A. Chassagne. 2014. "Air Tanker Drop Patterns". International Journal of Wildland Fire 23(2):272-280.

Martínez Oller, G. 2015. "Estudio de Eficiencia de Descargas de Agua de los Medios Aéreos de Extinción de Incendios". https://discovery.upc.edu/iii/encore/record/C_Rb1531284 accessed $19^{\text {th }}$ August 2020.

Masad, D., and J. Kazil. 2015. "Mesa: An Agent-Based Modeling Framework". In Proceedings of the 14th Python in Science Conference, July $6^{\text {th }}-12^{\text {th }}$, Austin, Texas. 51-58.

McArthur, A. G. 1962. "Control Burning in Eucalypt Forests". Leaflet. Forestry Timber Bureau, Australia.

Miller, C., J. Hilton, A. Sullivan, and M. Prakash. 2015. "SPARK - A Bushfire Spread Prediction Tool". In IFIP Advances in Information and Communication Technology, edited by R. Denzer, R. M. Argent, G. Schimak, and J. Hrebícek. $262-271$. Melbourne: Springer.

NFIC. 1996. "Wildland Fire Suppression Tactics Reference Guide". PMS 465, NFES 1256, National Wildfire Coordinating Group, Boise, Idaho. 


\section{Figueras, Guasch, and Casanovas-García}

Papadopoulos, G. D., and F. N. Pavlidou. 2011. "A Comparative Review on Wildfire Simulators". IEEE Systems Journal 5(2): 233-243.

Pierard, G., and A. Jarvis. 2010. "Study on Wild Fire Fighting Resources Sharing Models. Final report". https:/ec.europa.eu/echo/files/civil_protection/civil/prote/pdfdocs/future/Wildfire_Final_Report.pdf accessed August 19 ${ }^{\text {th }}$ 2020.

Richards, G. D. 1990. "An Elliptical Growth Model of Forest Fire Fronts and Its Numerical Solution". International Journal for Numerical Methods in Engineering 30(6):1163-1179.

Richards, G. D. 1995. "A General Mathematical Framework for Modeling Two-Dimensional Wildland Fire Spread". International Journal of Wildland Fire 5(2):63-72.

Rothermel, R. C. 1972. "A Mathematical Model for Predicting Fire Spread in Wildland Fuels". Research Paper, INT-115, Intermountain Forest and Range Experiment Station, Forest Service, U.S. Department of Agriculture, Ogden, Utah.

Simard, A. J. 1979. "A Computer Simulation Model of Forest Fire Suppression with Air Tankers". Canadian Journal of Forest Research 9(3):390-398.

Sneddon, I. N., B. B. Baker, and E. T. Copson. 1951. "The Mathematical Theory of Huygens' Principle". The Mathematical Gazette 35(311):67.

Steiniger, S., and A. J. S. Hunter. 2013. "The 2012 Free and Open Source GIS Software Map - A Guide to Facilitate Research, Development, and Adoption". Computers, Environment and Urban Systems 39:136-150.

Sullivan, A. L. 2009a. "Wildland Surface Fire Spread Modelling, 1990 - 2007. 1: Physical and Quasi-physical Models". International Journal of Wildland Fire 18(4):349-368.

Sullivan, A. L. 2009b. "Wildland Surface Fire Spread Modelling, 1990 - 2007. 2: Empirical and Quasi-empirical Models". International Journal of Wildland Fire 18(4):369-386.

Sullivan, A. L. 2009c. "Wildland Surface Fire Spread Modelling, 1990 - 2007. 3: Simulation and Mathematical Analogue Models". International Journal of Wildland Fire 18(4):387-403.

Suter, A. 2000. "Drop Testing Airtankers: a Discussion of the Cup-and-grid Method". Technology \& Development Program, U.S. Department of Agriculture, Forest Service, Missoula, Montana.

Tolhurst, K., B. Shields, and D. Chong. 2008. "Phoenix: Development and Application of a Bushfire Risk Management Tool". Australian Journal of Emergency Management 23(4):47-54

Tymstra, C., R. W. Bryce, B. M. Wotton, S. W. Taylor, and O. B. Armitage. 2010. "Development and Structure of Prometheus: the Canadian Wildland Fire Growth Simulation Model". Natural Resources Canada, Canadian Forest Service. Northern Forestry Centre, Information Report NOR-X-417, Edmonton, Alberta.

USDA. 2019. "Standards for Airtanker Operations". Technical Report 2019 revision. US Forest Service: Washington, D.C.

\section{AUTHOR BIOGRAPHIES}

JAUME FIGUERAS I JOVÉ is an Associate Professor and research engineer. His research is focused in and Computer Simulation and Optimization. He has designed and developed CORAL, an optimal control system for sewer networks, applied at Barcelona (Spain); PLIO, an optimal control system and planner for drinking water production and distribution, applied at Santiago de Chile (Chile) and Murcia (Spain). Nowadays He participates in different industrial projects, like the power consumption optimization of tramway lines in Barcelona with TRAM and SIEMENS and the development of tooPath a free web tracking system of mobile devices. He is also the local representative of OSM (http://www.openstreetmap.org) in Catalonia and participates in different FOSS projects. His email address is jaume.figueras@upc.edu.

ANTONI GUASCH I PETIT is a research engineer focusing on modelling, simulation and optimization of dynamic systems, especially continuous and discrete-event simulation of industrial processes. He received his PhD from the UPC in 1987. After a postdoctoral period at the State University of California (USA), he becomes a Professor of the UPC at the department of Automatic Control and the head of Simulation and Industrial Optimization at inLab FIB. Since 1990, Prof Guasch has lead more than 40 industrial projects related with modelling, simulation and optimization of nuclear, textile, transportation, car manufacturing, water and steel industrial processes. Prof. Guasch has also been the Scientific Coordinator and researcher in seven scientific projects He has participated in four EU projects, with the role of partner leader in two of them. Prof. Guasch currently research projected sponsored by Agbar is related to the development of optimization algorithms for agricultural land irrigation. Prof. Guasch is leading the development of tooPath, a web server system for the free tracking of mobile devices. The kernel of this tracking system is being used in a Web service developed for Alstom which tracks the position and speed of high speed trains in Spain and monitors the train's alarms.He is an Associate Professor in the Automatic Contol Dept. in the UPC. His email address is toni.guasch@upc.edu. 
JOSEP CASANOVAS-GARCÍA (Ph.D. in Computer Science, Industrial Engineer, MSc in Economics) is the head of inLab FIB, formerly called LCFIB, at Barcelona School of Informatics. He is a full professor of the Statistics and Operations Research Department at UPC. His main research areas are Modelling and Simulation, Internet and Information Systems. He is the author of numerous research articles and other kinds of publications and has collaborated in the development of many projects for the European Union and other companies and institutions. Between 1998 and 2004 he was dean of the Barcelona School of Informatics. In addition, Prof. Casanovas has been vice-rector of university policies of the Technical University of Catalonia (2006-2011) with responsibilities in strategic projects like the definition of new university governance models, reformulation of university departmental structure or design and promotion of the new Diagonal-Besos Campus in Barcelona. He was also responsible for ICT policies at UPC. Currently, Josep Casanovas is co-director of LogiSim (Centre of Simulation and Optimization of Logistic Systems) and coordinator of the Severo Ochoa Research Excellence Program in the Barcelona Supercomputing Center (BSC-CNS). He is the director of inLab FIB, a research lab particularly active in innovation and technology transfer to business. He's leading the HPC Modelling and Simulation for Social Sciences research group at Barcelona Supercomputing Center (BSC) His email address is josep.casanovas@upc.edu. 